\title{
Negotiating well-being: older people's narratives of relationships and relationality
}

To cite this article: Lizzie Ward (2014) Negotiating Well-being: Older People's Narratives of Relationships and Relationality, Ethics and Social Welfare, 8:3, 293-305, DOI:

10.1080/17496535.2014.932419

\section{Abstract}

This article discusses well-being in old age by drawing on findings from participatory research carried out by older co-researchers exploring how older people learn to sustain their own and others' well-being. It considers the way the in which research based in older people's experience can inform ethical policy and practice capable of delivering well-being. It critiques individualized notions of well-being and provides a counter- perspective based in relational understandings of what it is to be human drawn from feminist care ethics. This offers a different way of understanding the significance of social relationships and networks to older people's well-being from that offered by a focus on 'community' which has emerged in the communitarian discourses of the UK Coalition government. It illustrates this with older people's accounts of well-being highlighting the ways in which relationships with people, places and spaces are negotiated with ageing. Finally it argues that this relational conceptualization of well-being embodies values and the ethical dimensions of responsibility based in lived experiences. This provides the basis for alternative values-based policies and practices which we need to distinguish from the instrumental expression of social relationships and 'community' within communitarian discourses.

Keywords: older people, relational well-being, feminist care ethics, relationships, relationality 
Lizzie Ward is a Senior Research Fellow at the University of Brighton. She has been working on participatory research with older people since 2007 , and has recently completed an ESRC funded knowledge exchange which produced learning resources on older people's participation for social care practice.

Correspondence to: Lizzie Ward, School of Applied Social Science, Mayfield House, University of Brighton, BN1 9PH. Email: E.Ward@brighton.ac.uk

\section{Introduction}

The promotion of well-being has become recognized as a legitimate task of governments over recent years. In England the establishment of local Health and Well-being Boards and the re-branding of primary mental health provision as 'well-being services' are just two ways in which the notion of well-being has been embedded into the language of practice and intervention. Arguably, 'well-being services' aimed at improving mental health are relevant and applicable to the whole population, but in practice many are aimed at getting people (back) into work as part of the 'tackling worklessness agenda'. There has been less attention on what well-being might mean in later life when people are no longer working or how the social, psychological and physical changes that accompany ageing might impact on wellbeing. The aim of this article is to consider the ways in which research based in older people's experiences can inform ethical policy and practice capable of delivering well-being. It draws on findings from participatory research carried out by older co-researchers exploring how older people learn to sustain their own and others' well-being often in far from ideal circumstances. The analysis is based in feminist care ethics and challenges normative notions of independence and autonomy in later life by highlighting the significance of relationships and interdependency to well-being. 
Firstly, this article considers the links between well-being, independence and responsibility in relation to understanding ageing. It offers a brief overview of the way in which notions of individual well-being have dominated policy and research and provides a counterperspective based in relational understandings of what it is to be human drawn from feminist care ethics. It goes on to consider how this relational perspective offers a different way of understanding the significance of social relationships and networks to older people's well-being from that offered by a focus on 'community' which has emerged in the communitarian discourses of the UK Coalition government. It illustrates this with older people's accounts of well-being which highlight the ways in which relationships with people, places and spaces are negotiated with ageing. Finally it argues that this relational conceptualization of well-being embodies values and the ethical dimensions of responsibility based in lived experiences. This provides the basis for developing alternative values-based policies and practices which we need to distinguish from the instrumental expression of social relationships and 'community' within communitarian discourses. Thus, this article is not solely reporting on research findings but arguing for the ethical importance of researching in ways which enable people to explore understandings of well-being if we are to develop policy and practices capable of delivering well-being in old age.

\section{Ageing - independence, well-being and choice?}

The changing age distribution of the population, not only in western societies but in the rapidly ageing countries of the global south, is creating both personal and political challenges. At their most basic these can be understood to concern whether increasing 
longevity is something to be welcomed at an individual level, and something that is a 'good' for society in general. Is old age a time of personal well-being and is collective well-being enhanced by an increase in numbers of older people?

In the context of policy relating to ageing and older people, well-being in later life has primarily been linked to notions of independence and individual responsibility. The rational, choice making, self-governing individual conjured by neo-liberal public policies has found expression in a particular construction of 'active ageing'. This is based in the twofold aspiration that if we remain active as we grow older (work longer, look after their health by remaining physically active, take responsibility for others through family care and voluntary activity) then the quality of our life in old age will be better, and we will be less likely to become costly burdens on health and social care services. In common with international perspectives (WHO 2002), UK governments have set a policy framework which prioritises the concepts of independence, choice and autonomy and positions citizens as 'active consumers' of health and care services (e.g. DH 2005, 2006 ; DWP 2005).

There is a substantial body of work which critiques such individualistic notions of well-being (for example Edwards and Imrie 2008; Jordan 2008; Taylor 2011) yet until recently the focus on individual responsibility had become the policy orthodoxy in relation to ageing. However, in the wake of the financial crises, there has been a revival in ideas around 'community' solutions as relationships and social networks have begun to be acknowledged as aspects of well-being in UK policy (DH 2010a, b; HM Government 2010). In setting out its post-financial crash vision, the UK coalition government has turned to communitarian philosophy to mobilize notions of community and mutuality to meet the shortfall in public resources. 
Older people are summoned to do their bit to solve the problems of austerity not only by limiting the demands they make on public services, but also by contributing through volunteering, grand-parenting and in other ways being active, responsible citizens. However, research drawing primarily on older people's lived experiences, suggests older people already make substantial, if generally unrecognized, contributions through care and volunteering (Ward, Barnes and Gahagan 2012; Breheny and Stephens 2009; Lloyd et al. 2014; Lloyd 2012; Tanner 2010). It is important to understand older people are active agents and contributors to social well-being (Phillipson 2013) but equally important to understand the challenges that older people are negotiating to achieve well-being in reducing circumstances - at both an individual or interpersonal level but also due to austerity cutbacks.

There is a need to develop a critical perspective on the idea that older people are going to solve the problems of austerity by volunteering whilst recognizing that older people are active contributors to society as well as needing care and support. The ways in which older people themselves talk about well-being and how it is generated in old age challenges the way that notions of dependency and burden are employed in dominant policy discourses. This will be illustrated later in the article by drawing on research findings which highlight the ways older people talked about negotiating both care-giving and care-receiving. Their accounts reflect the values implicit in these negotiations and offer examples from lived experience which could inform the development of ethical policy making and practice (Barnes and Yeatman 2013). 


\section{Relational well-being and an ethic of care}

The emergence of well-being as a policy objective has generated an industry devoted to ways in which this can be measured, compared and linked both to specific practices and to broader measures of economic and social 'performance' (Barnes, Taylor and Ward 2013). What is common to the diverse measures and varying concepts on which these are based, is that well-being is conceived as an individual quality. That is, its presence or absence is determined by individual assessments of subjective states according to a pre-defined set of criteria. Such measures are largely static. People are considered within a horizontal time/ space frame rather than one that is multidimensional, multidirectional, and shaped both by past, present and future. Subjective well-being is seen primarily as an outcome of individual action, rather than as being produced through close and distant relationships with others (Taylor 2011), or through people's relationships with their past and future selves, and with the places in which they live and through which they move.

Critiques of individualized conceptions of persons are being advanced from different ideological and theoretical positions (for example Donati 2011). Similarly, there are important bodies of work that emphasise the necessity of encompassing both affective and value based understandings of human relations in order not only to better understand these, but also to generate policies and practices capable of producing well-being and social justice (Sayer 2011). This article draws on work informed by feminist care ethics to highlight the significance of care to well-being in diverse contexts, including situations in which older people give care to spouses, children and friends, as well as through voluntary activity, and situations in which they learn to receive care from others (Barnes 2012). The significance of this body of work is that it has: 
"....developed an analysis of care as a political as well as a personal practice and [has] argued the necessity of care to social justice, based on an analysis of dependency and interdependency, rather than autonomy, as fundamental to human survival and wellbeing." (Barnes 2012, 11).

Feminist care ethics is based in a relational ontology that more closely reflects lived experience and lay values than either ethical or policy discourses that assume equality, autonomy and abstract principles as the basis for social relations (Kittay 1999; Tronto 1993, 2013). It engages with the emotional and embodied nature of intimate personal relationships, with the tensions that arise from vulnerability and unequal power, as well as the ethical principles shaping policy decisions. Its application across a range of policy, practice and lived experience contexts demonstrates its utility in providing both an analytical framework and a guide to practice (Koggel and Orme 2010).

Further, and in the context of this article and the study informing it, a relational ethics of care develops an understanding of what is involved in the negotiation of relationships as we age. This includes changes to self, identity and the need for care, as well daily interactions in the spaces and places of everyday life, all of which impact on our relationships and ultimately our well-being. Care ethics alerts us to the complexity and context specific nature of these negotiations, and recognises the differential power dynamics in play.

\section{Communities, places and relationships}

There has been an upsurge of work within gerontology that recognises the significance of place and space in understanding the experiences of ageing (Andrews, Evans and Wiles 
2013; Buffel, Phillipson and Scharf 2012; Holland et al. 2007; Keating 2008; Liddle et al. 2013; Means and Evans 2012; Smith, 2009). Place has often been equated with community in studies of older people's experiences of being included within or excluded from both the physical and social environments in which they live, although Means and Evans (2012) have argued the importance of recognising 'communities of interest' as well as place in considering older people's continuing engagement in social, economic and cultural life. Andrews, Evans and Wiles (2013) argue that whilst the spatial orientation within gerontology is developing it has so far been limited by 'bounded and static understandings of 'space' and 'place" $(2013,1340)$. Combining insights from care ethics with their consideration of relationality and affect in approaching the significance of place and space in older age offers a helpful way forward. But not only do we need research that adopts 'a relational approach to space and place and an associated focus on affect' (ibid, 1361), we also need to encompass the ethical dimensions of relationality in order to consider the interaction between place, social and personal relationships, and well-being.

An enduring critique of the concept of community has been the failure to recognise the descriptive, normative and instrumental uses of the term (Taylor 2003). Although ostensibly a response to a dominant individualism, communitarian philosophy has promoted conservative social relations, through obscuring the way in which social relations of gender, 'race', ability/disability and sexuality structure forms of domination and oppression. Kittay (2001) has distinguished the relational basis of care ethics from communitarianism on these grounds. But we do need a social concept of place and space that can enable us to comprehend the importance of these to older people's well-being as well as the significance 
of relationships with people. Before exploring this through empirical findings the next section gives more detail of how the research informing this article was undertaken.

\section{Researching well-being with older people}

The project on which this article is based involved participatory research in which older people were co-producers of knowledge. The aims of the research were to understand older people's perspectives on well-being and develop insight into how people seek to maintain a sense of well-being as they age. We also wanted to generate knowledge about participatory research practice and we conducted the project within relationships embodying principles of care ethics and which contributed to well-being as well as enabling understanding of this (Ward and Gahagan 2010). It involved a collaboration between university researchers, a voluntary sector manager and a team of 12 older co-researchers aged early 60 s to late 80 s. The co-researchers contributed to design, data collection, analysis, produced written outputs, and presented findings at conferences and seminars. This was not just a matter of including the co-researchers in a set of activities, but was also about the nature of the relationships we developed during the process, how these were connected to our subject matter and developing our understanding of well-being and ethical research practice. It involved being attentive not only to the different contributions that team members felt comfortable in making, and to the practical support necessary to enable them to work with us, but how we could ensure their well-being through the ways in which we worked together. Thus the process of working together contributed understanding to the way in which well-being can be generated amongst older people and within inter-generational relationships. 
Our approach of working with older people as co-researchers impacted the knowledge we generated in a number of ways. In the early stages of the project team meetings focused on developing the research design and as part of this process we tried out one of the instruments that has been used to measure older people's well-being - CASP 19, to explore whether team members thought that would be useful for our purposes. They rejected this for a number of reasons. They thought completing it might detract from well-being as it would cause older people to focus on negatives; they suggested people's responses would be impacted by immediate circumstances and not reflect the 'ups and downs' of well-being, and they commented on the absence of any recognition of the significance of relationships. After further discussion we agreed on semi-structured interviews and focus groups using an approach that invited participants to talk about what well-being meant to them and the circumstances in which this is generated. A topic guide was developed based on team discussions to enable exploration and dialogue about what older people themselves identified as important.

The co-researchers carried out interviews with 30 people aged 67 to 97 . A further 59 people took part in focus groups. The interviews were transcribed and coded thematically. Interview coding was shared with some team members contributing to this and the academic researcher providing an overview to ensure consistency. Coded sections of transcripts were then organised under themes and brought to team meetings for discussion. These discussions not only enabled the development of more insightful interpretations of what interviewees were saying, but also provoked personal reflections from team members 
and different responses to the issues raised that produced a deeper insight into the processes through which well-being is generated.

In addition to the thematic analysis we undertook a narrative analysis on seven interviews looking at each as a whole and the nature of the stories that run through them. This revealed how issues such as people's experiences of poor health - their own or that of close relatives; their feelings about where they live; or their responses to the social changes taking place around them, interact in the context of their lived lives. They offer accounts of well-being that highlight the significance of being able to make sense of life changes over time and thus the need to understand well-being not as a steady state, but as a dynamic process of responding, adapting and negotiating.

\section{Older people's accounts of well-being}

Interviewees were invited to share their ideas about well-being by reflecting on circumstances in which they experienced this. A number of interconnected themes repeatedly appeared in the participant's descriptions. For example, within an overarching theme of relationships, interviewees spoke about relationships with family, friends, serviceproviders, neighbours as well as with the spaces and places of everyday life - the home, the local neighbourhood, and public spaces. Participants talked about well-being as something that is created between and through people, in relationships to others and the social worlds we inhabit, rather than something than can be understood solely in individual terms. Participants' accounts also highlighted the significance of changes over time, and the dynamic processes that involve adapting to transitions that come with ageing. Both positive memories of the past and anxieties about the future can impact well-being. 
The stories people told also reflected the impact of life long experiences of difference. For a woman with learning disabilities who 'found' a family for the first time in old age, having lived most of her life in residential care, ageing was associated with improved well-being because of changed attitudes towards people with a learning disability. A gay man in his 70s also reflected on the impact of more positive attitudes, but also on ageism within the gay community. A full account of the research findings can be found in Ward, Barnes and Gahagan (2012) and the next sections of the article discuss the ways in which relationships with people, places and spaces are negotiated, highlighting the values implicit in these negotiations. Together they illustrate the relational aspects of well-being.

\section{Care as a 'lens' to understand relational well-being}

Drawing on Barnes (2012) care is conceptualized here as a quality in relationships; as a set of values; and as a practice. Our analysis explored the ways care was talked about to illustrate the extent to which well-being (and its lack) was generated through relationships and produced through the more subtle features and processes of care giving and receiving. All the participants talked about care in some way - either receiving support for themselves, giving care to others, such as spouses, adult children or grandchildren, or in some cases both giving and receiving care. Care encompassed more than what is typically understood as personal care, health or nursing care, and included feeling 'cared for' and 'caring about' others. It was spoken about in the context of close relationships -family, friends, and partners - as well relationships with formal service providers and 'strangers'. 
Whilst care in the broadest sense is necessary for everyone across the life course, participants described changes in the significance of care as they had aged. For some, ill health, deteriorating long-term conditions or acute and unexpected episodes, had increased their need for health care. Others talked about increasing needs for support with daily living. They distinguished functional help from support that was given with care. Many had also experienced significant changes in their lives as a result of their spouse's ill health and becoming a care-giver.

Some were looking after grandchildren on a regular basis, including those, like Elsie $^{1}(81)$ who had significant health issues following a stroke, and Ruby (84) whose arthritis impacted her mobility. Many described the continuing roles they played in their adult children and grandchildren's lives, being able to offer support and advice as well as helping out practically with childcare. Caring relationships were thus within and across generations.

Participants' accounts highlighted the complex negotiations with self and others in the processes of giving and receiving care. It became clear that negotiating 'caring relationships' could involve moral dilemmas, be fraught with tension, and be emotionally demanding. The degree to which care was experienced positively or problematically, largely depended on these processes. For those who associated receiving care with a loss of independence and undermining of personal identity, it could be hard to ask for and accept care. Recognizing care needs and learning to accept care, which might involve role reversals within a relationship, were clearly difficult processes. This was clearly illustrated in relationships with

\footnotetext{
1 Names are pseudonyms, ages are in brackets
} 
adult children. Pam, for example, who was 79 and widowed, explained how she had resisted the idea that her son should care for her when she was taken ill:

'he is my next of kin and that was the number l'd given ... I picked the phone up and said just stay where you are my boy, there's never been an occasion in my life when I'm going to disrupt your life and lifestyle to come and look after me. If I need any help I'll get it some other way so you do not come home'.

There were examples of care that was experienced as a process through which people were not only helped, but valued, in contrast with accounts that suggested help was given grudgingly or in a way that contributed to older people feeling a burden. This was particularly evident in Grace's story. Grace, who was 97 at the time of interview, lived alone and managed her daily tasks without help. She said she would 'rather crawl on the floor' than ask for help from her son and daughter-in-law, and that if she did ask she felt like she was being a 'nuisance'. In contrast, she spoke positively of being taken shopping by a young friend who made her feel 'like the queen' on such occasions.

Some interviewees could compensate negative feelings associated with needing care through continuing to help others - small exchanges of help - 'giving back' in other ways, and by volunteering. This supports findings from other studies which have highlighted the role of reciprocity in later life (Breheny and Stephens 2009; Lloyd et al. 2014; Tanner 2010). The care that Elsie received from her family felt less like a burden as she felt she still had an important role within her family as mother and grandmother. This helped her in coming to terms with the losses she had experienced and what she described as feeling like 'my life is over now' following a stroke. However, whilst helping others could enhance feelings of self- 
worth, the expectation that this is something people should do created a sense of lack of value for those who were not able or limited in what they could to for others. Grace, who was made to give up voluntary work at 93 , expressed this as feeling like she had 'outlived my purpose'.

One of the challenges of ageing is the loss of relationships. Many of the participants, and in particular those in their 90s, had outlived friends, siblings, and spouses. Along with losing a shared history and a sense of being 'known' which are fundamental aspects of self-identity, the loss of a role as a carer could also have negative impacts on well-being. For example, Joan (74) who had cared for her husband for six years before he died said that she missed having someone to care for. Others, like Rose (69) and Jennifer (76), described the difficult and challenging work of being a full-time carer and the range of emotional responses it generated including resentment, anger and frustration. Neither had ever imagined being in this position. Dealing with their sense of duty and the expectation that they would care for their husbands was made more difficult by a reversal in gendered expectations within their relationships.

\section{Spaces and places of everyday life and well-being}

The second way in which well-being can be considered as relational is through a focus on older people's relationships with space and place. These issues arose in the ways in which participants talked about where they live, their homes, how they get about, places that give them pleasure, and how they try to maintain contact with people over long distances. In these aspects of their accounts they were reflecting on their relationships with and within spaces and places, and how these impact their well-being. 
One example is the decisions some had made about moving to sheltered housing. This was seen as a way of becoming less isolated, perhaps making new friends. But in practice the design of this accommodation and the 'turnover' of people living there meant people continued to feel isolated. Ethel (96) had had many friends amongst her neighbours in the sheltered housing she had moved into twenty years previously but 'they've all gone... everybody that was there when I went there twenty years ago they've more or less all died'. Feeling secure at home depended to a large extent on contacts beyond the home and having people nearby who can be called on for help. Connie (87) who lived alone explained that 'unless they (her neighbours) see my bedroom window open, [they] are in here like a shot. So I am not worried about being alone'. The age difference between these two women illustrates the necessary of understanding the interaction between space and time in relation to this dimension of well-being.

Beyond the 'close' space of home, participants also talked about the importance of public spaces in their local areas. Some spoke about the challenges of being able to get to particular places, of negotiating distance, public transport, traffic and busy streets. These accounts highlighted connections between places and the desire for continuity to sustain identity and well-being. Seemingly everyday tasks, such as going into town shopping held an emotional significance beyond the immediate purpose. For example Jacob (96) described how he and his wife liked to buy fish from a particular shop and the great efforts it took them to continue to do this. Others, like Ethel (96) remembered favourite places that connected to their past, 'I mean I'd love to go down the pier, I think the pier's lovely. I always used to sit on the pier, take a book and have a sandwich, sit right at the water'. 
Public spaces also provided opportunities for interactions with others, casual encounters with 'strangers' at bus stops and in the street that also impacted well-being. Charles (79) for example, spoke about avoiding self-service checkouts at the supermarket as he liked the human contact and having 'a bit of banter with the checkout people'.

The participants' accounts contained a strong emotional dimension. This illustrated ways in which they were adjusting and adapting to changes in both themselves and the world around them, highlighting the dynamic and interconnected processes of the spatial aspects of ageing. Space and place impacted older people's well-being through their ability to feel a sense of continuity in self-identity, feeling security in knowing that others 'notice' them, and being able to remain connected to others. This adds an important dimension to the way we might conceptualise the meaning of 'community'.

\section{Discussion}

The overall findings from this study reveal the challenges faced by many older people in maintaining a sense of well-being in later life. They also enable us to start to theorise relational well-being in terms of the multiple relationships that are necessary to this, reflecting the significance of distant as well as intimate relationships. This challenges normative assumptions which equate well-being in old age with independence and active ageing and locate responsibility for these with the individual. The participants' accounts offer insights into the way in which social relations, and the way in which interactions with physical space impact older people's well-being, and their capacity to contribute to that of others. They also provide a more complex picture than the vision promoted in recent policy 
drives to 'build resilient communities' to sustain care so that 'people and communities' play 'more of a role in supporting themselves and others' (DH 2010b 9).

Some have argued that the resurgence in communitarianism and the recognition of social relationships needs to be understood within the context of the post 2008 financial crisis, which shook the fundamental underpinnings of neo-liberalism (Davis 2012). At first sight the 'new' focus on social relationships may appear to resonate with the narratives of older people in this study and the argument of this article that well-being needs to be understood as a relational concept. However, it is crucial to bear in mind that the emerging communitarian policy framework is informed ideologically by a commitment to reduce the responsibility of resourcing care away from the state and as a justification for further cuts in public resources. This signifies a continuing commitment to neo-liberal imperatives. In contrast, within feminist care ethics responsibility is understood as inherently bound to the political, democratic and ethical significance of care as a collective responsibility, including the responsibilities of states to enable care for citizens (Tronto 2013).

There is a real difficulty here given the relentless discourse on the 'burden' of the ageing population and the lack of recognition to the actual contribution older people are already making. It is clearly important to counter the negative constructions of ageing and stigmatising of older people by pointing this out. Yet it also remains vital to highlight the fact that at some stage in later life it is very likely that every person will need care.

Finally, the importance of hearing the lived experiences of older people is crucial to understanding that part of the challenge of ageing is that it takes place within an ageist 
society and that in so many ways the realities of ageing are poorly understood or largely ignored. Whilst the relational well-being deriving from the interactions described by our participants is experienced subjectively by individual older people, they have a collective significance and an ethical dimension. The lack of recognition of older people, what was described as 'becoming a non person' by one of the interviewees, amounts to cultural or symbolic injustice (Fraser, 1997). To overcome this form of injustice requires a transformation of social relations in a way that reflects the relational qualities necessary to well-being. Feminist care ethics offers a framework within which we can understand how relational well-being can be enhanced in old age and inform alternative values-based approaches to policy and practice development.

\section{Acknowledgements}

I would like to express my gratitude and thanks to Marian Barnes for helpful comments on earlier drafts, and to Beatrice Gahagan, Age UK Brighton and Hove all the members of older people's co-research group for their collaboration on this project.

\section{References}

Andrews, G. J., Evans, J. and Wiles, J.L. 2013 “Re-spacing and re-placing gerontology: relationality and affect." Ageing and Society 33 (8):1339 - 1373.

Barnes, M. 2012. Care in Everyday Life. An ethic of care in practice. Bristol: Policy Press. Barnes, M., Taylor, D. and Ward, L. (2013) "Being well enough in old age" Critical Social Policy, 33, 473- 493.

Barnes, M. and Yeatman, A. 2013. "Editorial" Ethics and Social Welfare 7 (2):107-108. 
Breheny, M., and Stephens, C. 2009. "'I sort of pay back in my own little way': managing independence and social connectedness through reciprocity." Ageing and Society 29: 1295 1313.

Buffel, T., Phillipson, C. and Scharf, T. 2012. “Ageing in urban environments: developing 'age-friendly' cities.” Critical Social Policy. 32 (4): 597-617.

Davies, W. 2012. "The Emerging Neocommunitarianism." The Political Quarterly 83 (4): 767776.

Department for Work and Pensions (DWP). 2005. Opportunity Age: Meeting the Challenges of Ageing in the 21st Century. London: Department for Work and Pensions.

Department of Health (DH). 2005. Independence Well-Being and Choice: Our Vision for the Future of Adult Social Care in England. London: Department of Health.

Department of Health (DH). 2006. Our Health, Our Care, Our Say. London: Department of Health.

Department of Health (DH). 2009. Shaping the Future of Care Together. London: Stationery Office.

Department of Health (DH). 2010a. A Vision for Adult Social Care: Capable Communities and Active Citizens. London: Department of Health.

Department of Health (DH). 2010b. Practical Approaches to improving the lives of disabled and older people through building stronger communities. London: Department of Health. Donati, P. 2011. Relational Sociology: A New Paradigm for the Social Sciences. London: Routledge.

Edwards, C. and Imrie, R. 2008."Disability and the implications of the wellbeing agenda: some reflections from the United Kingdom." Journal of Social Policy 37: 337 - 55. Fraser, N. 1997. Justice Interruptus: critical reflections on the "postsocialist" condition. New 
York: Routledge.

Gough, I., and McGregor, A. eds. 2007. Wellbeing in Developing Countries: From Theory to Research. Cambridge: Cambridge University Press.

HM Government (HMG). 2010. Healthy lives, healthy people: Our strategy for public health in England. London: Stationery Office.

Holland, C., Clark, A., Katz, J. and Peace, S. 2007. Social interactions in urban public places. Public Spaces. Bristol, UK: Policy Press.

Jordan, B. 2008. Welfare and Well-being Social value in public policy. Bristol: Policy Press. Keating, N., ed. 2008. Rural Ageing. A good place to grow old? Bristol: Policy Press.

Kittay, E. F. 1999. Love's Labor. Essays on Women, Equality and Dependency. New York: Routledge.

Kittay, E. F. 2001. "A Feminist Public Ethic of Care Meets the New Communitarian Family Policy." Ethics 111 (3): 523-547.

Koggel, C., and Orme, J. 2010. "Editorial. Care Ethics: New Theories and Applications." Ethics and Social Welfare 4 (2): 109-114.

Liddle, J., Scharf, T., Bartlam, B., Bernard, M. and Sim, J. 2013. “Exploring the agefriendliness of purpose built retirement communities: evidence from England". Ageing and Society: 129 doi: $10.1017 / \mathrm{S} 0144686 \times 13000366$.

Lloyd, L. 2012. Health and Social Care in Ageing Societies: A new international approach. Bristol: Policy Press.

Lloyd, L., Calnan, M., Cameron, A., Seymour, J. and Smith, R. 2014. "Identity in the fourth age: perseverance, adaptation and maintaining dignity." Ageing and Society 34 (1): 1 - 19. Means, R., and Evans, S. 2012. “Communities of place and communities of interest? An exploration of their changing role in later life." Ageing and Society 32 (8): 1300-1318. 
Sayer, A. 2011. Why Things Matter to People: Social Science, Values and Ethical Life.

Cambridge: Cambridge University Press.

Smith, A. E. 2009. Ageing in Urban Neighbourhoods. Place, attachment and social exclusion.

Bristol: Policy Press.

Tanner, D. 2010. Managing the ageing experience: learning from older people. Bristol: Policy Press.

Taylor, D. 2011. "Wellbeing and welfare: a psychosocial analysis of being well doing well enough." Journal of Social Policy 40 (4): 777 - 794.

Taylor, M. 2003. Public Policy in the Community. Basingstoke: Palgrave.

Tronto, J. C. 1993. Moral Boundaries. A Political Argument for an Ethic of Care. New York:

Routledge.

Tronto J.C. 2013. Caring Democracy. Markets, Equality and Justice, New York: New York.

Ward, L. and Gahagan, B. 2010. “Crossing the Divide between Theory and Practice: Research and an Ethic of Care." Ethics and Social Welfare 4 (2): 210-216.

Ward, L., Barnes, M. and Gahagan, B. 2012. Well-being in Old Age: Findings from

participatory research. University of Brighton and Age UK Brighton \& Hove,

http://www.brighton.ac.uk/sass/older-people-wellbeing-and-participation/

World Health Organisation (WHO). 2002. Active Ageing: A Policy Framework. Geneva: WHO. 